\title{
Exploring the causes of flow attenuation at a beaver dam sequence.
}

\author{
Hugh Graham ${ }^{1}$, Alan Puttock ${ }^{1}$, Mark Elliott ${ }^{2}$, Karen Anderson $^{3}$, and Richard Brazier ${ }^{1}$ \\ ${ }^{1}$ University of Exeter College of Life and Environmental Sciences \\ ${ }^{2}$ Devon Wildlife Trust \\ ${ }^{3}$ University of Exeter Environment and Sustainability Institute
}

February 17, 2022

\begin{abstract}
Beavers influence hydrology by constructing woody dams. Using a before after control impact experimental design, we quantified the effects of a beaver dam sequence on the flow regime of a stream in SW England. Building upon our previous research (Puttock et al., 2021), we consider the mechanisms that underpin flow attenuation in beaver wetlands. Rainfall-driven hydrological events were extracted between 2009 and 2020, for the impacted $(n=612)$ and control $(n=634)$ catchments, capturing events seven years before and three years after beaver occupancy, at the impacted site. General additive models were used to describe average hydrograph geometry across all events. After beaver occupancy, Lag times increased by $55.9 \%$ and declined by $17.5 \%$ in impacted and control catchments, respectively. Flow duration curve analysis showed a larger reduction in frequency of high flows, following beaver dam construction, with declines of Q5 exceedance levels of $33 \%$ and $15 \%$ for impact and control catchments, respectively. Using event total rainfall to predict peak flow, five generalised linear models were fitted to test the hypothesis that beaver dams attenuate flow, to a greater degree, with larger storm magnitude. The best performing model showed we can have high confidence that beaver dams attenuated peak flows, with increasing magnitude, up to between 0.5-2.5 $\mathrm{m}^{3} \mathrm{~s}^{-1}$ for the $94^{\text {th }}$ percentile of event total rainfall; but we cannot confidently detect attenuation beyond the $97^{\text {th }}$ percentile. Increasing flow attenuation, with event magnitude, is attributed to transient floodplain storage in low gradient/profile floodplain valleys. These findings support the assertion that beaver dams restore attenuated flows. However, with long-term datasets of extreme hydrological events lacking, it is challenging to predict the effect of beaver dams during extreme events with high precision. Beaver dams will have spatially variable impacts on hydrological processes, requiring further investigation to quantify responses to dams across differing landscapes and scales.
\end{abstract}

\section{Hosted file}

Graham_et_al_FlowAttenuationBeaver_HP_S1.docx available at https://authorea.com/users/461087/ articles/556861-exploring-the-causes-of-flow-attenuation-at-a-beaver-dam-sequence 

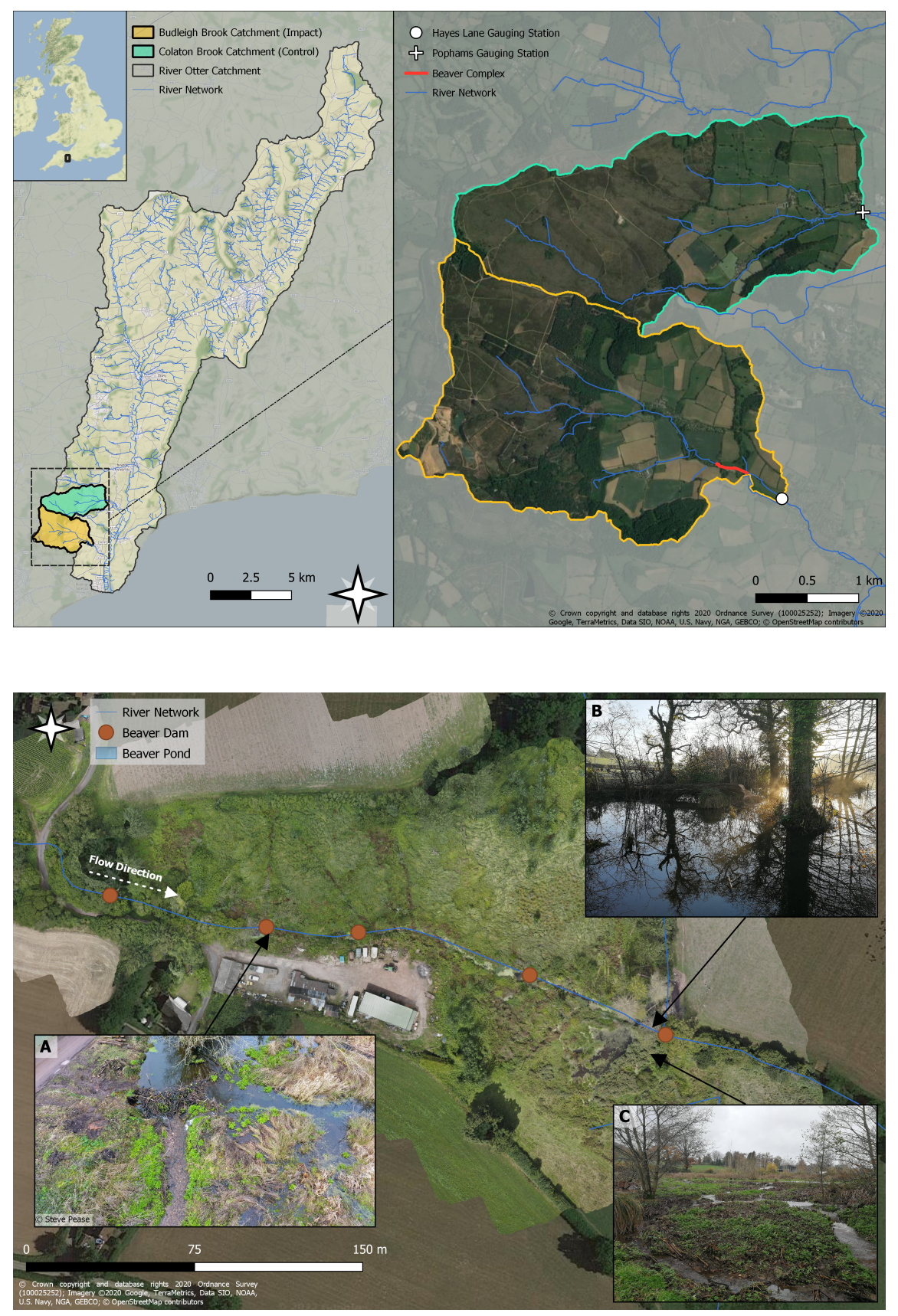

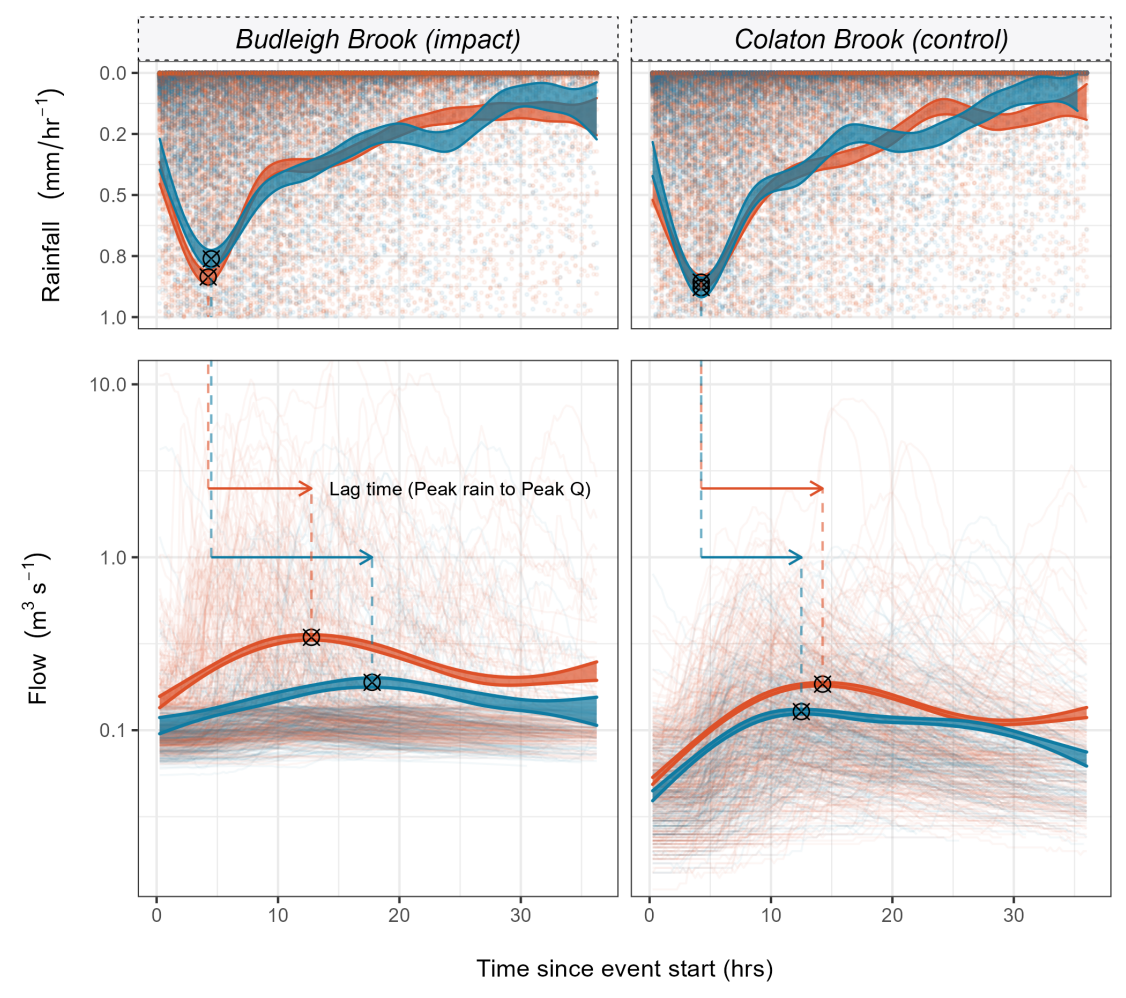

Beaver Status at Impacted Site $\square$ Absent $\square$ Present

@ GAM Hydrograph Peak Q and Rainfall 


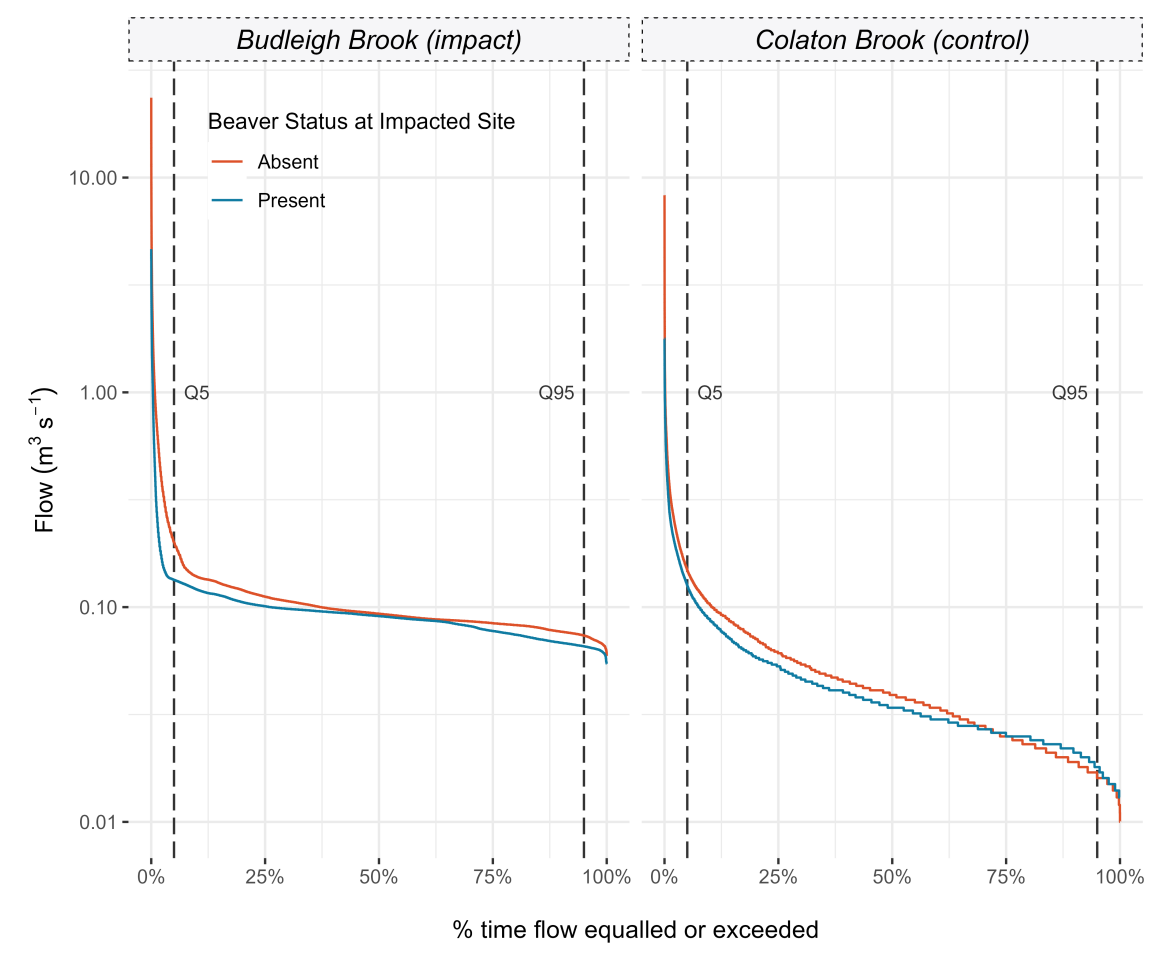



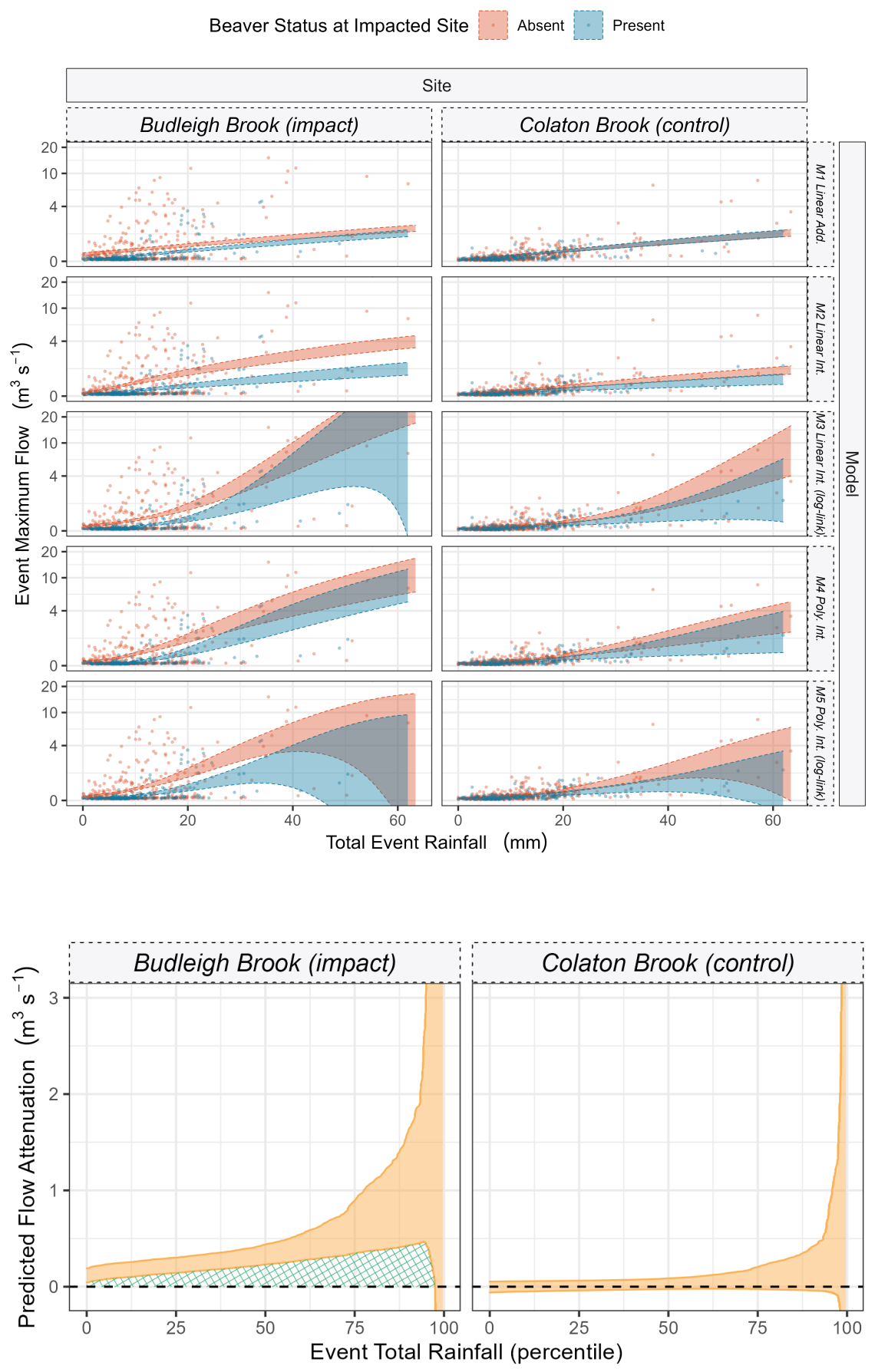

Attenuation Effect

$95 \%$ confidence range 


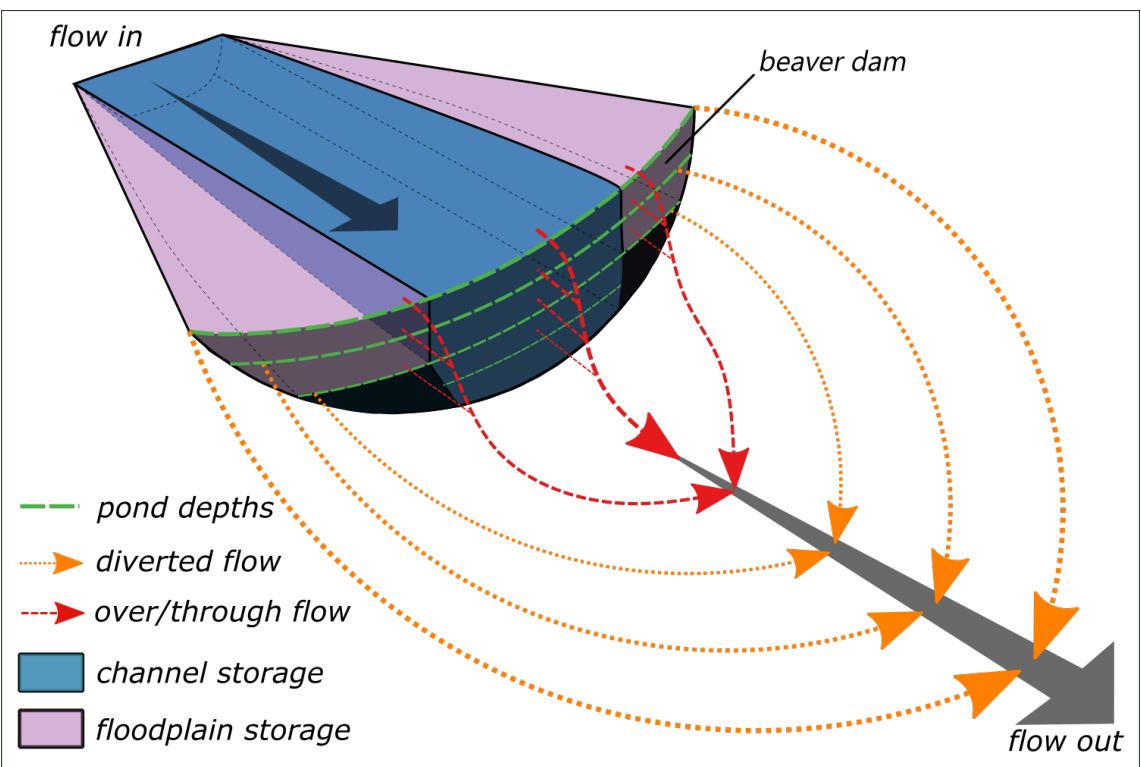

